\title{
Structural Performance of RC Beams containing Tension-Only Nodes
}

\author{
Manuel Alejandro Fernández-Ruiz* ${ }^{\oplus}$, Luisa María Gil-Martín, and Enrique Hernández-Montes
}

\author{
(Received December 16, 2016, Accepted November 3, 2017)
}

\begin{abstract}
Strut and Tie (S\&T) models are used for the design of what are known as "discontinuity regions" in reinforced concrete (RC) structures. Building codes such as ACI-318 and Eurocode 2 do not give information on the nodes that only connect ties in S\&T models (called TTT or tension-only nodes). However, their use is not explicitly prohibited in the design of RC structures. In this work, a comparison between solutions which have been designed both considering and not considering TTT nodes is evaluated. Four RC beams (designed with and without TTT nodes) were subjected to three-point bending. Experimental results show that TTT nodes are a good design solution for special cases of discontinuity regions in RC structures. However, the experimental campaign has proven that this type of node is more vulnerable to errors during construction than solutions designed without TTT nodes.
\end{abstract}

Keywords: discontinuity region, reinforced concrete, TTT nodes, strut and tie model.

\section{Introduction: Continuity and Discontinuity Regions}

Strut and tie (S\&T) models (Schlaich et al. 1987) may be used for the design in the ultimate limit state (ULS) of discontinuity regions [ACI-318 $\$ 23$ (ACI Committee 318 2014) and Eurocode 2 \$5.6.4(1) (CEN 2004)] in Reinforced Concrete (RC) structures. The S\&T method is based on the lower bound plasticity theorem. As an unlimited number of possible S\&T models can be inserted into a discontinuity region, a correct definition of the S\&T model during the design process is key for a good estimation of the loadcarrying capacity of the corresponding RC member (Kassem 2015; Choi et al. 2012).

The shear reinforcement calculated using S\&T models or beam theory is similar in the case of structural elements which have a constant cross-section. Therefore, in these cases, engineers do not make an explicit distinction between continuity regions and discontinuity regions. Nevertheless, this is not always the case. If shear reinforcement based on the plain section hypothesis (beam theory) is designed, its uniform distribution along the length of the member can lead to failure, as in Fig. 1. In this example, the shear reinforcement should have been placed right at the point of discontinuity, but this was not the case. It is clear that the failure in Fig. 1 was due to a lack of reinforcement in a zone that demanded concentrated reinforcement. It is likely that

Department of Structural Mechanics, University of Granada (UGR), Campus Universitario de Fuentenueva s/n, 18072 Granada, Spain.

*Corresponding Author; E-mail: malejandrofr@ugr.es Copyright (c) The Author(s) 2018. This article is an open access publication this failure would not have occurred if this D region had been studied using a proper S\&T model.

Nodal zones in a S\&T model are a design idealization of a more complex stress state in the regions where the demand is concentrated, due to a change in the load path (Yun 2006).

Elements, such as the girder shown in Fig. 1, can be designed using S\&T models containing TTT nodes. A scale model of the previous girder is shown in Fig. 2. Figure 3 shows two girders with two different solutions using S\&T models (considering and not considering TTT nodes, type A and B specimens respectively), both girders have the geometry shown in Fig. 2.

Several S\&T models, compatible with both the geometry and reinforcement, have been analyzed by authors but only the ones represented in Fig. 3 are going to be considered in this work. All of them satisfy the ACI (ACI Committee 318 2014) requirements on angles between struts and ties, the length of the ties is at a minimum in order to avoid excessive deflections, and in both of them, the yielding of the ties happens before the failure of the struts.

\section{Materials and Methods: Design with TTT Nodes}

Theoretically a S\&T model could include TTT (or tensiononly) nodes, but the reality is that there are no specific recommendations in structural codes for concrete, such as ACI-318 (ACI Committee 318 2014) and Eurocode 2 (CEN 2004). Furthermore, there are few pieces of research and documents like that of Bergmeister et al. (Bergmeister et al. 1993), that recognize the possibility of using TTT nodes in the design of RC structures. 


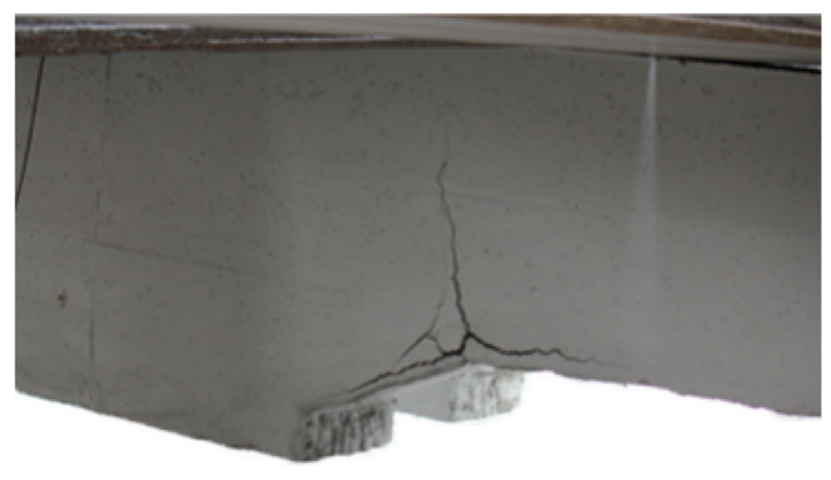

Fig. 1 Failure due to lack of reinforcement.

In order to understand the behaviour of this type of node, four specimens have been designed, tested and analyzed in the Structures Laboratory of the University of Granada. The geometry of the specimens is shown in Fig. 2. The specimens were subjected to three-point bending (see Fig. 4).

Two specimens were designed using a S\&T model that includes TTT nodes (specimens A-I and A-II, see Fig. 3a) and the other two were designed using a S\&T model that does not include TTT nodes (specimens B-I and B-II, see Fig. 3b). The self-weight of each specimen was considered in its individual design and, for the sake of simplicity, each one was modelled as a punctual load acting on the upper nodes of the model (see the grey arrows in Fig. 3). The reinforcement layout and the location of the strain gauges are indicated in Fig. 5. The yield strength of the steel bars used in this work was experimentally determined from tensile tests, with $f_{y}=534.5 \mathrm{MPa}$. The compressive strength of concrete was $f_{c}^{\prime}=22.89 \pm 0.81 \mathrm{MPa}$ for type A specimens and $f_{c}^{\prime}=25.65 \pm 0.83 \mathrm{MPa}$ for type $\mathrm{B}$ specimens. The nomenclature used for the strain gauges is as follows: A and B indicate the specimens, ST and SL identify strain gauges in stirrups and in longitudinal reinforcement, respectively. Strain gauges placed into the bars in front of the specimen are identified with 1 and the ones placed into the bars behind are called 2 (see Fig. 5). The number after the last hyphen corresponds to the number of each strain gauge. Both specimens were designed to sustain a similar ultimate load, according to ACI-318 (ACI Committee 318 2014) code, type A specimens had $32 \%$ less steel in their weight than type B specimens.
Specimens A-I and A-II are slightly different. The stirrup corresponding to the TTT node 12 of specimen A-II (see Fig. 3a) was positioned $1.8 \mathrm{~cm}$ from the change of direction of the bent longitudinal bars. This node is called "defective TTT node” hereafter. However, specimens B-I and B-II are identical.

\section{Results and Discussion}

\subsection{S\&T Model}

The width of struts was computed following AASHTO prescriptions (AASHTO 2012) and the structural capacity of struts, ties and nodes was computed according to ACI-318 (ACI Committee 318 2014) (see Appendix). According to ACI-318 (ACI Committee 318 2014), if more than three forces act on a nodal zone it can be assumed that all of them act through the same point or, alternatively, some of them can be resolved to form three intersecting forces. Due to the high value of the angles between the axis of the truss members of both S\&T models proposed in Fig. 3, the first option has been adopted in this work.

$P_{y i e l d, S \& T}$ is the load at midspan that causes first yielding in any nodal region, strut or tie, which has been obtained from the S\&T analysis which takes the actual yield strength of steel into account. For the models represented in Fig. 3, $P_{\text {yield }, S \& T}$ is $74.5 \mathrm{kN}$ for type A specimens and $71.6 \mathrm{kN}$ for type B specimens. In the case of type A specimens, $P_{\text {yield,S\&T }}$ corresponds to the yielding of the tie between the nodes 7 and 10 (see Fig. 3a). In the case of type B specimens, the value of $P_{y i e l d, S \& T}$ corresponds to the yielding of the tie between the nodes 5 and 8 and its symmetrical counterpart (the tie between the nodes 10 and 14), see Fig. $3 \mathrm{~b}$.

\subsection{Experimental Results}

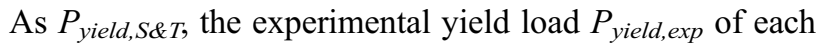
beam corresponds to the load leading to the first yield at a tie, strut or nodal zone. The experimental value of $P_{\text {yield,exp }}$ was determined using the data recorded by the strain gauges located at the tie that first yielded during the tests (with the yielding of the tie having happened prior to the failure at any strut or nodal region). The values of $P_{\text {yield,exp }}$ are summarized in Table 1 for each beam tested.

Positioning the stirrup wrongly (in this case, a displacement around $20 \mathrm{~mm}$ ) in the TTT node provoked a reduction

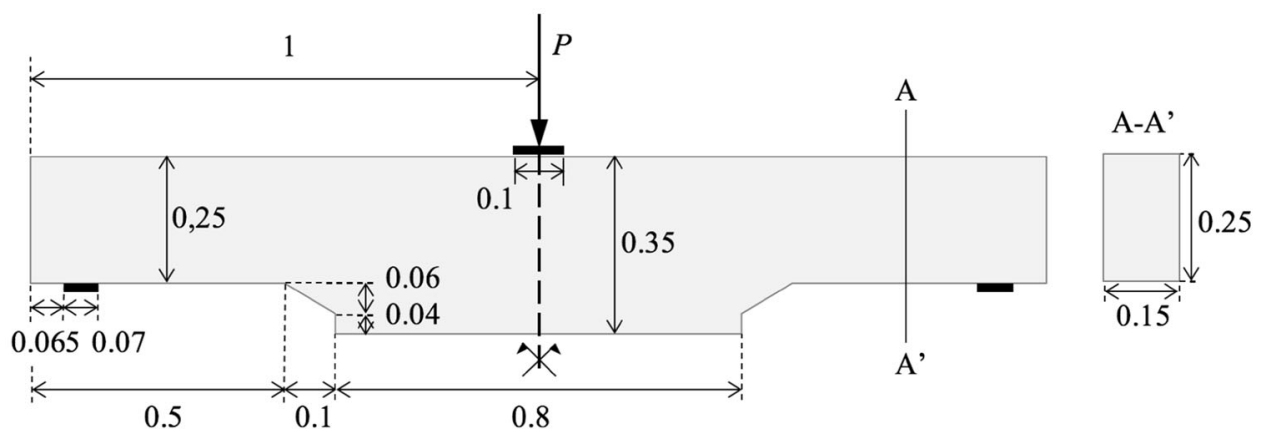

Fig. 2 Geometry of the RC beam (dimensions in $\mathrm{m}$ ). 

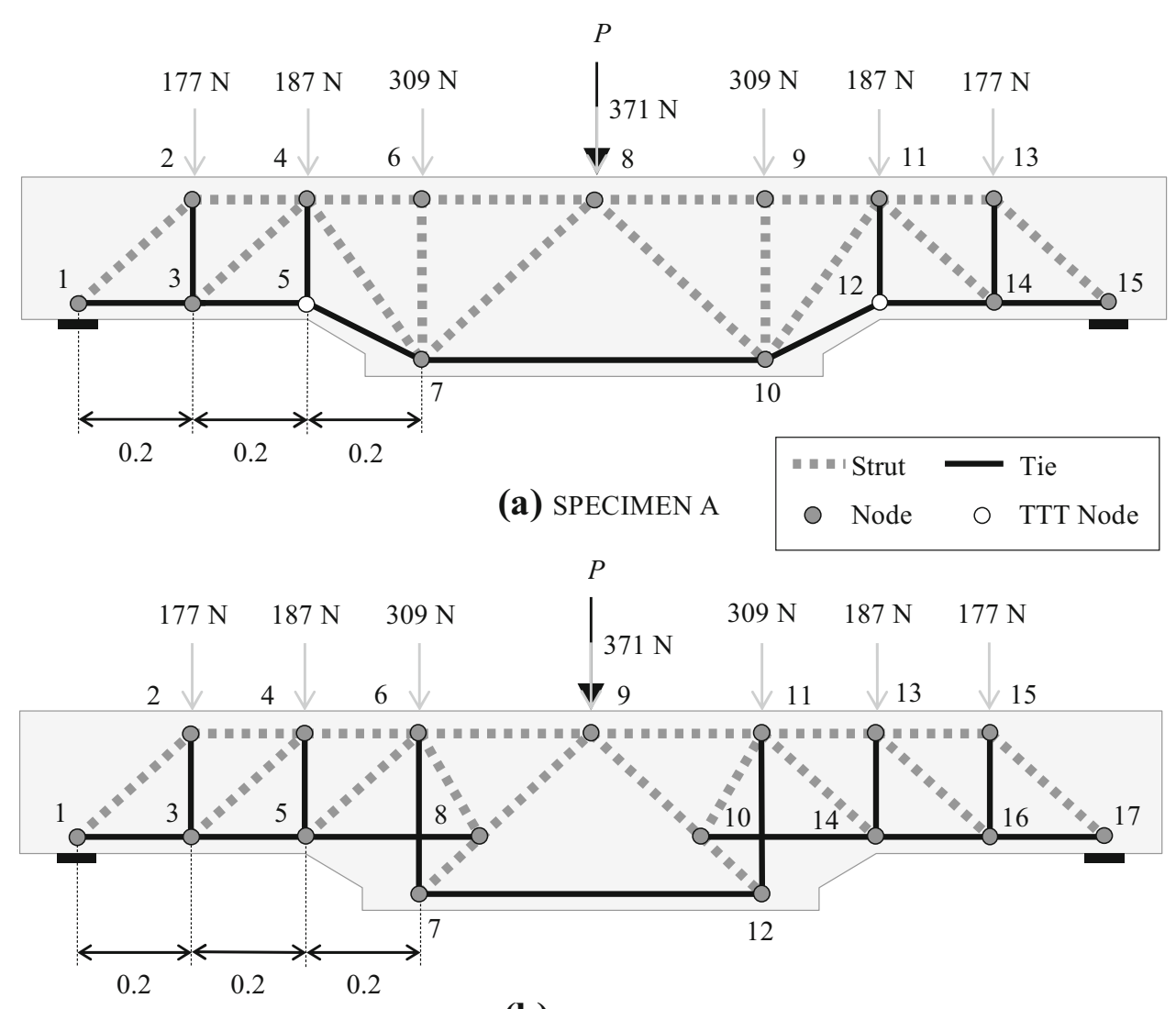

(b) SPECIMEN B

Fig. 3 Girder with geometrical discontinuity a solved considering TTT nodes, b solved not considering TTT nodes. The grey arrows correspond to the self-weight of the beam and load $P$ corresponds to the applied load.

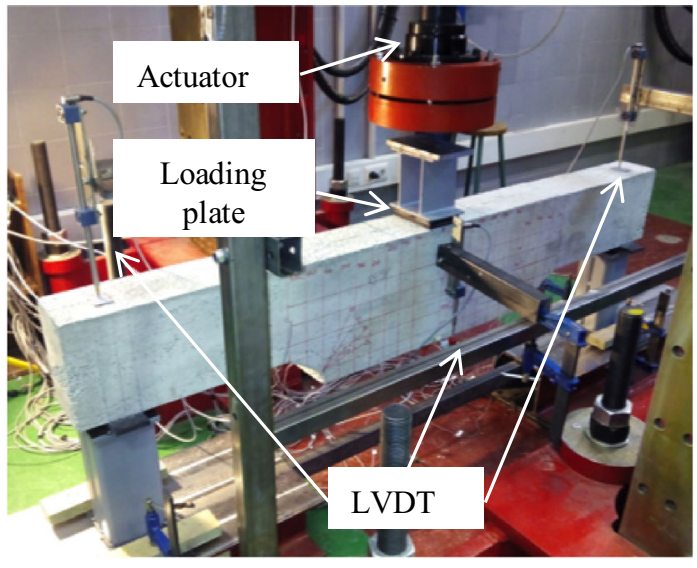

Fig. 4 Test setup.

in the yield load of the beam of around $18 \%$ (see Table 1). Specimens A-I, B-I and B-II had a similar $P_{\text {yield,exp, even }}$ though $32 \%$ in the weight of reinforcing steel was saved in the case of A-I compared with type B specimens.

As was expected, the yield loads estimated using the S\&T models were slightly lower than the corresponding experimental results (see Table 1) in all cases except for specimen A-II (the specimen with the defective TTT node). The accuracy of the yield load obtained from the S\&T models presented in Fig. 3 depends on how well they represent the internal stresses of the tested beams. Results corresponding to specimen A are closer to the experimental ones than those of specimen B, meaning that the first model more accurately represents the internal behavior of the beam.

As the applied load increases, the internal stresses of the beam change. The appearance of load transfer mechanisms different from those considered in the S\&T models presented in Fig. 3 could explain the difference between analytical and experimental values.

Load versus midspan deflection curves obtained from the specimens tested are shown in Fig. 6. At midspan, Specimen A-I developed a higher deflection than type B specimens under the same load. Nevertheless, it is evident that the difference between the deflections of A-I and type B specimens is small (less than $2 \mathrm{~mm}$ throughout the whole test).

Figure 7 shows the recorded strain at the positions of some representative strain gauges as a function of the load applied for the tested specimens. The yielding of the reinforcement for both type A specimens started at the tie between the nodes 7 and 10 (strain gauge A-SL2-3). However, the yielding of the reinforcement for both type B specimens started at the tie between nodes 10 and 14 and almost simultaneously at the tie between nodes 5 and 8 (strain gauge B-SL2-3). Both experimental results coincide with the predictions from the S\&T models. 


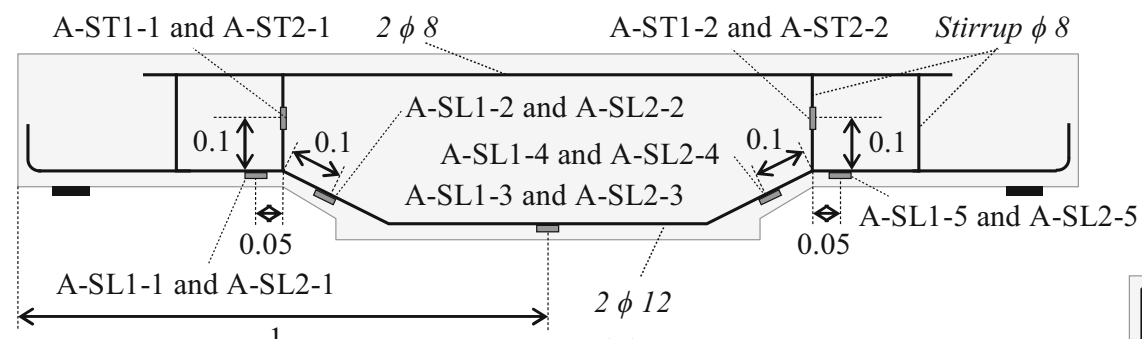

(a)

$$
2 \phi 8 \quad \text { B-ST1-3 and B-ST2-3 }
$$

B-ST1-1 and B-ST2-1 B-ST1-2 and B-ST2-2 B-ST1-4 and B-ST2-4 Stirrup $\phi 8$

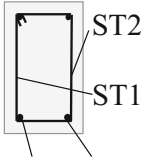

SL1 SL2

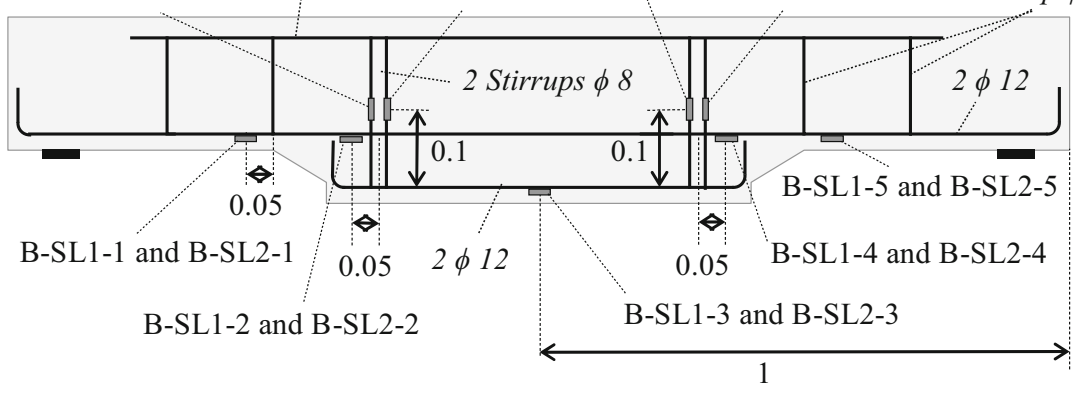

(b)

Fig. 5 Reinforcement layout and location of strain gauges. a Type A specimens. b Type B specimens.

Table 1 Summary of test results.

\begin{tabular}{c|c|c}
\hline Specimen & $P_{\text {yield,S\&T }}$ & $P_{\text {yield,exp }}$ \\
\hline \hline A-I & 74.5 & 84.5 \\
\hline A-II & 74.5 & 69.6 \\
\hline B-I & 71.6 & 88.4 \\
\hline B-II & 71.6 & 86.6 \\
\hline
\end{tabular}

${ }^{\text {a }}$ Defective TTT Node.

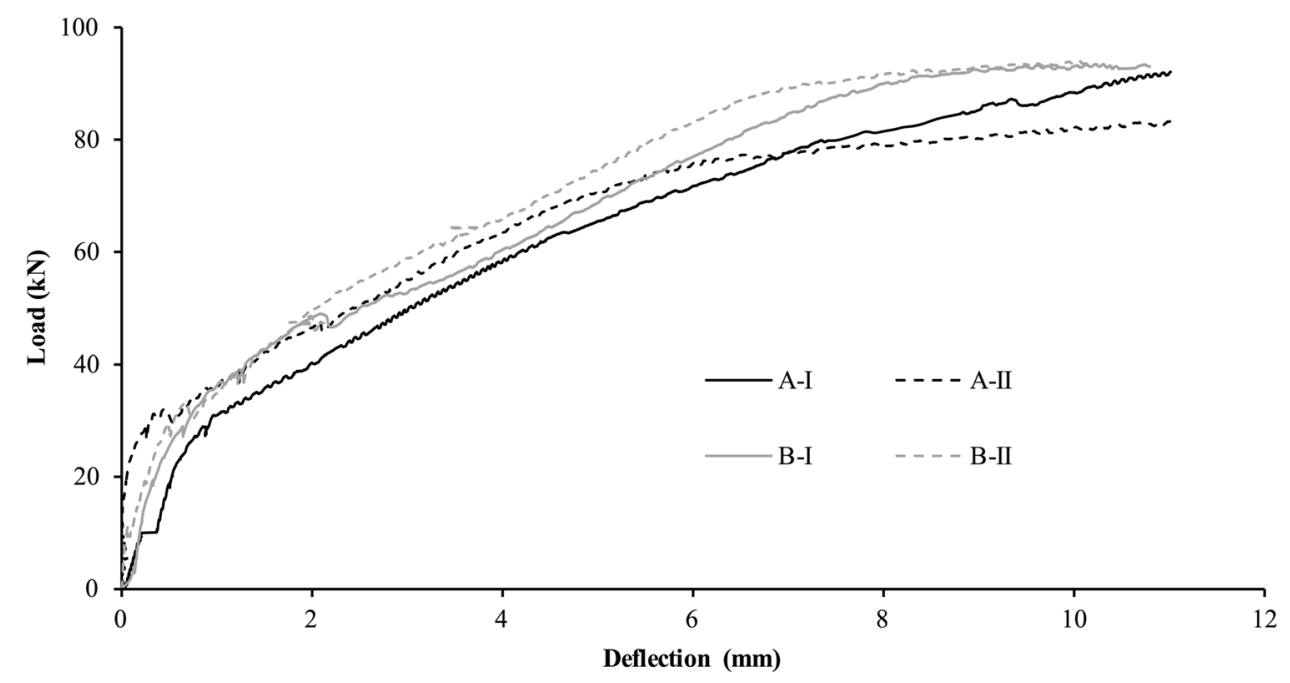

Fig. 6 Load-midspan deflection curves of type A and B specimens. 


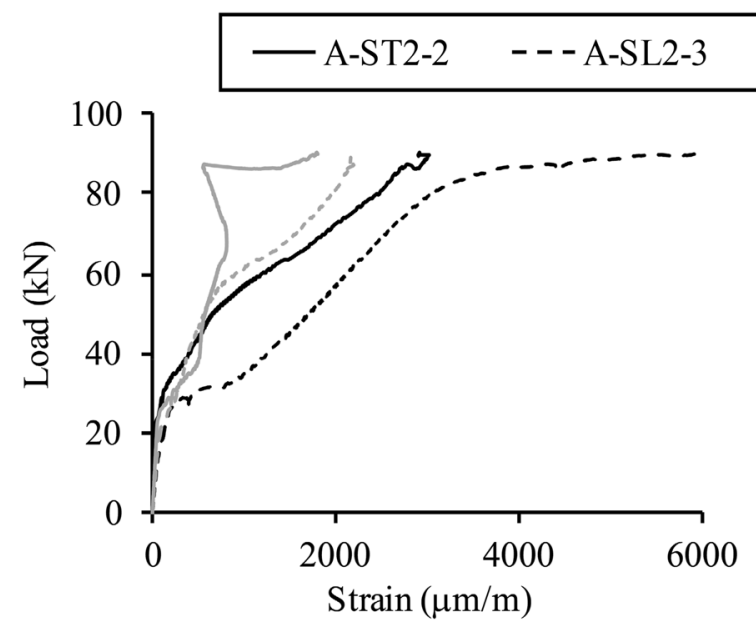

(a)

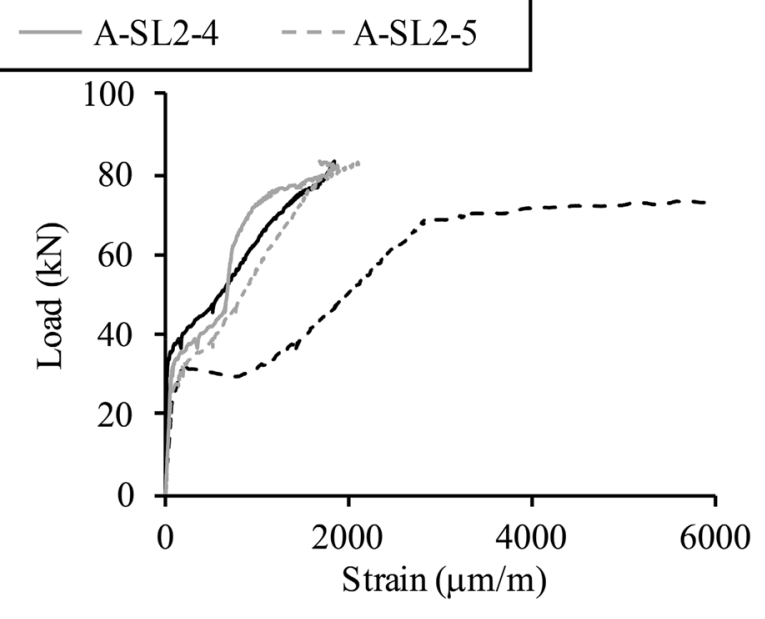

(b)

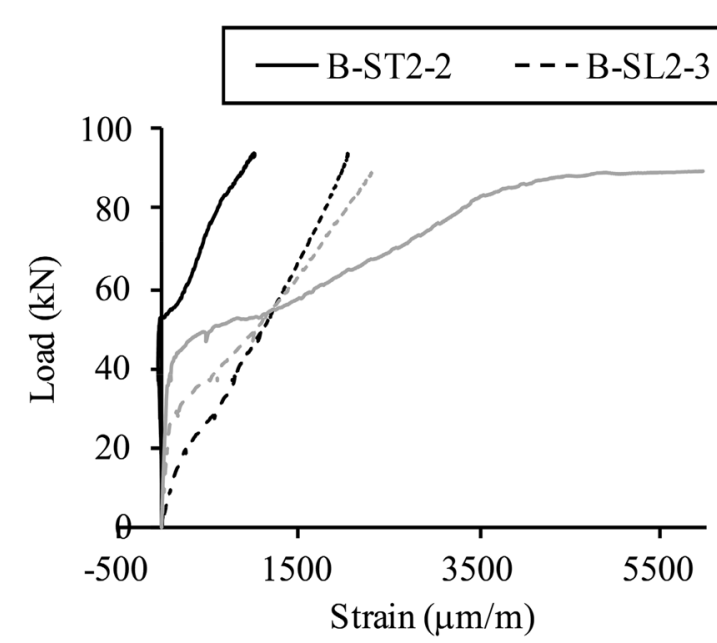

(c)

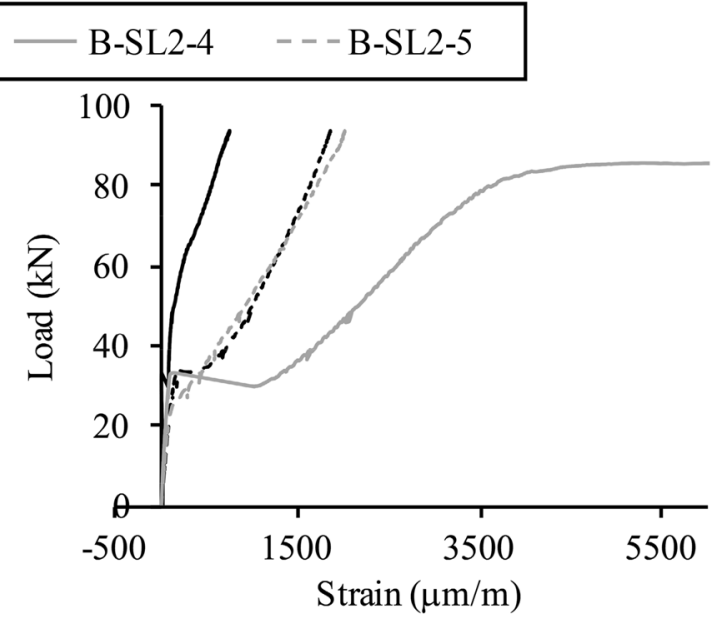

(d)

Fig. 7 Measured strains as a function of the load applied. a Specimen A-I. b Specimen A-II. c Specimen B-I. d Specimen B-II. The position of each gauge is indicated in Fig. 5.

\section{Conclusions}

The main structural codes, such as ACI-318 and Eurocode 2 do not provide design guidelines for TTT nodes. Four RC beams with varying cross-sections designed using S\&T models including (A-I and A-II specimens) and not including (B-I and B-II specimens) tension-only nodes were subjected to three-point bending in the Structures Laboratory of the University of Granada.

Experimental results showed that elements including TTT nodes are more vulnerable to errors during construction than models that do not include TTT nodes. Specimen A-II (with a defective TTT node) had a $18 \%$ reduction of the yield load compared with specimen A-I (without a defective TTT node).

Specimen A-I had a yielding capacity similar type B specimens (with even a saving of $32 \%$ in the weight of steel).

Two S\&T models, both considering and not considering TTT nodes were proposed to predict the yielding capacity of A and B specimens in Fig. 3. Both the yielding capacities and the failure modes obtained from S\&T models and experimental tests were in reasonable correlation.

Tension-only nodes can be considered in the design of discontinuity regions in RC members in some cases (like the one presented) but a more exhaustive control during the construction procedure is required. 


\section{Acknowledgements}

The authors would like to acknowledge the financial support provided by the University of Granada in the form of a PhD fellow (FPU Grant) to the first author.

\section{Open Access}

This article is distributed under the terms of the Creative Commons Attribution 4.0 International License (http:// creativecommons.org/licenses/by/4.0/), which permits unre stricted use, distribution, and reproduction in any medium, provided you give appropriate credit to the original author(s) and the source, provide a link to the Creative Commons license, and indicate if changes were made.

\section{Appendix A.1: Check of Strut and Tie Strength}

Member dimensions, stress limits and the quantity of reinforcement provided are presented in Table 2 for both the S\&T models considered in this work. For the sake of symmetry, only one half of the truss members are included in Table 2. The node numbers and the location of nodes in this table correspond to those previously defined in Fig. 3.

\section{Appendix A.2: Check of Nodal Zones}

The strength capacity of some representative nodal zones has been computed and summarized in this Appendix.

\section{Specimen B, Nodal Zone 9 (CCC Node), Fig. 8}

The effective compressive strength of concrete at face of a nodal zone $f_{c e}$ has been computed using the following expression according to ACI-318 (ACI Committee 3182014 ):

$$
f_{c e}=0.85 \beta_{n} f_{c}^{\prime}
$$

In the case of a nodal zone bound by struts, bearing areas or both (CCC nodes), $\beta_{n}=1$ and $f_{c e}=21.80 \mathrm{MPa}$. The widths, $w_{s}$, and stresses, $f_{n}$, in each truss member shown in Fig. 8 are as follows:

$$
\begin{aligned}
& w_{s 6-9}=w_{s 9-11}=80 \mathrm{~mm} \\
& w_{s 8-9}=w_{s 9-10}=l_{b} \sin (\alpha)+h_{a} \cos (\alpha)=127 \mathrm{~mm}
\end{aligned}
$$

$$
f_{s 6-9}=F_{s 9-11}=\frac{F_{s 9-11}}{b w_{s 9-11}}=6.49 \mathrm{MPa}<21.80 \mathrm{MPa}
$$

\begin{tabular}{|c|c|c|c|c|c|c|c|c|c|}
\hline \multicolumn{5}{|c|}{ Specimen A } & \multicolumn{5}{|c|}{ Specimen B } \\
\hline \multicolumn{2}{|c|}{ End nodes } & \multirow{2}{*}{$\begin{array}{l}\text { Type } \\
\text { Strut }\end{array}$} & \multirow{2}{*}{$\begin{array}{c}\begin{array}{c}\text { Design } \\
\text { details }\end{array} \\
64(2)\end{array}$} & \multirow{2}{*}{$\begin{array}{c}\mathrm{D} / \mathrm{C} \\
0.5\end{array}$} & \multicolumn{2}{|c|}{ End nodes } & \multirow{2}{*}{$\begin{array}{l}\text { Type } \\
\text { Strut }\end{array}$} & \multirow{2}{*}{$\begin{array}{l}\begin{array}{c}\text { Design } \\
\text { details }\end{array} \\
64(2)\end{array}$} & \multirow{2}{*}{$\begin{array}{c}\mathrm{D} / \mathrm{C} \\
0.43\end{array}$} \\
\hline 1 & 2 & & & & 1 & 2 & & & \\
\hline 1 & 3 & Tie & $2 \phi 12$ & 0.35 & 1 & 3 & Tie & $2 \phi 12$ & 0.34 \\
\hline 2 & 3 & Tie & Stirrup $\phi 8$ & 0.71 & 2 & 3 & Tie & Stirrup $\phi 8$ & 0.68 \\
\hline 2 & 4 & Strut & 80 & 0.30 & 2 & 4 & Strut & 80 & 0.26 \\
\hline 3 & 4 & Strut & $64(4)$ & 0.50 & 3 & 4 & Strut & $64(4)$ & 0.43 \\
\hline 3 & 5 & Tie & $2 \phi 12$ & 0.69 & 3 & 5 & Tie & $2 \phi 12$ & 0.67 \\
\hline 4 & 5 & Tie & Stirrup $\phi 8$ & 0.78 & 4 & 5 & Tie & Stirrup $\phi 8$ & 0.68 \\
\hline 4 & 6 & Strut & 80 & 0.58 & 4 & 6 & Strut & 80 & 0.52 \\
\hline 4 & 7 & Strut & $78(4)$ & 0.04 & 5 & 6 & Strut & $64(6)$ & 0.43 \\
\hline 5 & 7 & Tie & $2 \phi 12$ & 0.78 & 5 & 8 & Tie & $2 \phi 12$ & 1.00 \\
\hline 6 & 7 & Strut & $96(6)$ & 0.01 & 6 & 7 & Tie & 2 Stirrups $\phi 8$ & 0.97 \\
\hline 6 & 8 & Strut & 80 & 0.58 & 6 & 9 & Strut & 80 & 0.50 \\
\hline 7 & 8 & Strut & $98(7)$ & 0.32 & 6 & 8 & Strut & 83 & 0.52 \\
\hline \multirow[t]{3}{*}{7} & 10 & Tie & $2 \phi 12$ & 1 & 7 & 8 & Strut & 98 & 0.98 \\
\hline & & & & & 8 & 9 & Strut & 98 & 0.27 \\
\hline & & & & & 7 & 12 & Tie & $2 \phi 12$ & 0.44 \\
\hline
\end{tabular}

$$
f_{s 8-9}=F_{s 9-10}=\frac{F_{s 9-10}}{b w_{s 9-10}}=2.76 \mathrm{MPa}<21.80 \mathrm{MPa}
$$

Table 2 Member dimensions, stress limits and reinforcement provided for both the S\&T models presented in Fig. 3.

Notes Design details: Strut lesser width at each end of the strut in mm (node with lesser width), ties number and size of bars $\phi=$ diameter of the bars); $D / C$ ratio of demand/capacity. 


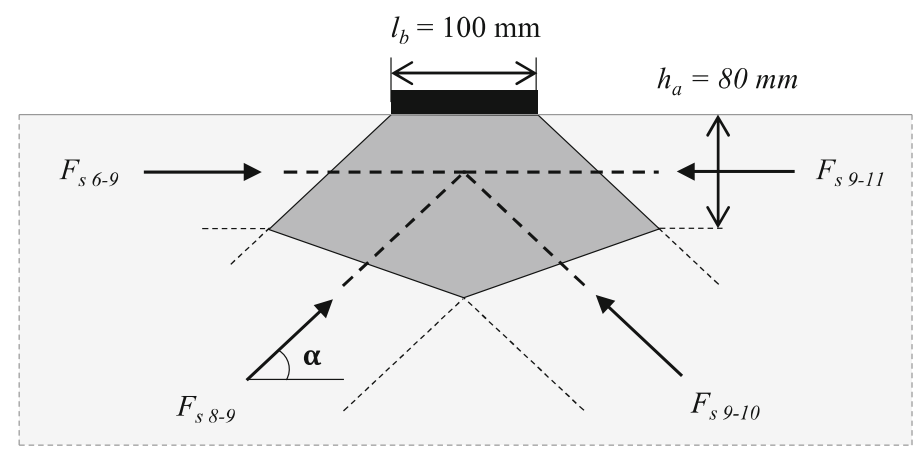

Fig. 8 Nodal zone 9 in type B specimen.

As can be seen in Eqs. A-4 and A-5, the stress at any face of the nodal zone is lower than $f_{c e}$.

\section{Specimen A, Nodal Zone 1 (CCT), Fig. 9}

In the case of a nodal zone anchoring one tie $\beta_{n}=0.8$ and $f_{c e}=15.57 \mathrm{MPa}$ (Eq. A-1), the widths, $w_{s}$, and stresses, $f_{n}$, in each truss member shown in Fig. 9 are as follows:

$$
\begin{array}{rlr}
w_{s 1-2}=l_{b} \sin (\alpha)+h_{\alpha} \cos (\alpha)=90 \mathrm{~mm} & (\mathrm{~A}-6) \\
w_{t 1-3}=58 \mathrm{~mm} & (\mathrm{~A}-7) \\
F_{s 1-2}=\frac{F_{s 1-2}}{b w_{s 1-2}}=4.21 \mathrm{MPa}<15.57 \mathrm{MPa} & (\mathrm{A}-8)
\end{array}
$$

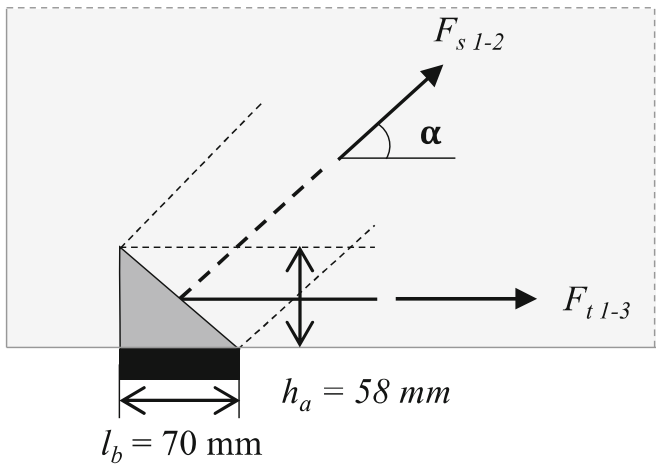

Fig. 9 Nodal zone 1 in specimen type A.

$$
F_{t 1-3}=\frac{F_{t 1-3}}{b w_{t 1-3}}=4.84 \mathrm{MPa}<15.57 \mathrm{MPa}
$$

As can be seen in Eqs. A-8 and A-9, the stress at all of the nodal zones is lower than $f_{c e}$.

Specimen B, Nodal Zone 5 (CTT node), Fig. 10

In the case of a nodal zone anchoring one tie $\beta_{n}=0.6$ and $f_{c e}=13.08 \mathrm{MPa}$ (Eq. A-1). The widths, $w_{s}$, and stresses, $f_{n}$, in each truss member shown in Fig. 10 are as follows:

$$
\begin{array}{ll}
w_{t 3-5}=58 \mathrm{~mm} & (\mathrm{~A}-10) \\
w_{t 4-5}=\frac{F_{t 4-5}}{b f_{c e}}=19 \mathrm{~mm} & (\mathrm{~A}-11) \\
w_{s 5-6}=l_{a} \sin (\alpha)=6 \phi 2 \sin (\alpha)=97 \mathrm{~mm} & (\mathrm{~A}-12) \\
w_{t 5-8}=80 \mathrm{~mm} & (\mathrm{~A}-13) \\
f_{t 3-5}=\frac{F_{t 3-5}}{b w_{t 3-5}}=9.29 \mathrm{MPa}<13.08 \mathrm{MPa} & (\mathrm{A}-14) \\
f_{t 4-5}=\frac{F_{t 4-5}}{b w_{t 4-5}}=13.08 \mathrm{MPa} & (\mathrm{A}-15) \\
f_{s 5-6}=\frac{F_{s 5-6}}{b w_{s 5-6}}=3.72 \mathrm{MPa}<13.08 \mathrm{MPa} & (\mathrm{A}-16) \\
f_{t 5-8}=\frac{F_{t 5-8}}{b w_{t 5-8}}=10.08 \mathrm{MPa}<13.08 \mathrm{MPa} & (\mathrm{A}-17)
\end{array}
$$

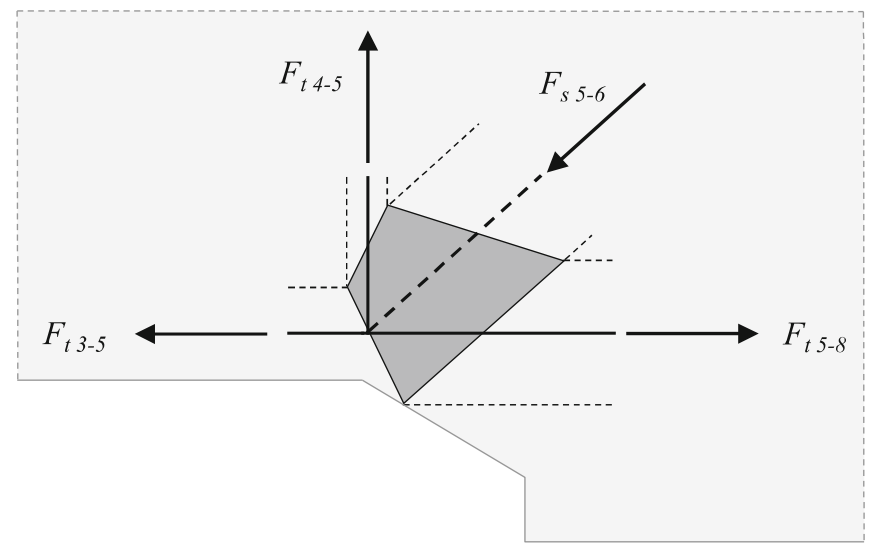

Fig. 10 Nodal zone 5 in specimen type B. 
As can be seen from Eqs. A-14 to A-17, the stress at all of the nodes is lower than $f_{c e}$. The width of the tie between nodes 4-5 has been computed considering the yielding of the tie (for this reason $f_{t 4-5}=f_{c e}$ ). This is a limit value; the width of the tie can increase (it is not limited by the boundary of the section), and consequently is $f_{t 4-5}<f_{c e}$.

\section{Specimen A, Nodal Zone 5 (TTT node)}

In order to properly design the TTT node, the ties in node 5 should comply with the anchorage details given in $\$ 8.5(2)$ of Eurocode 2 (CEN 2004). Accordingly, it can be concluded that the structural safety of TTT nodes is assured if deformation of the ties that converge at a node does not reach the yield strain.

\section{References}

AASHTO. (2012). AASHTO LRFD bridge design specifications. Washington, DC: American Association of State Highway and Transportation Officials.

ACI Committee 318. (2014). Building code requirements for structural concrete (ACI 318-08). Farmington Hills, MI: American Concrete Institute.
Bergmeister, K., Breen, J. E., Jirsa, J. O., \& Kreger, M. E. (1993). Detailing for structural concrete, Center for Transportation Research Report 0-1127-3F. Austin: University of Texas.

CEN. (2004). Eurocode 2: Design of concrete structures - Part 1-1. General rules and rules for buildings UNE-EN 1992-11. Brussels: European Committee for Standardization.

Choi, Y. W., Lee, H. K., Chu, S. B., Cheong, S. H., \& Jung, W. Y. (2012). Shear behavior and performance of deep beams made with self-compacting concrete. International Journal of Concrete Structure Materials, 6, 65-78. https://doi.org/ 10.1007/s40069-012-0007-y.

Kassem, W. (2015). Strength prediction of corbels using strutand-tie model analysis. International Journal of Concrete Structure Materials, 9, 255-266. https://doi.org/10.1007/ s40069-015-0102-y.

Schlaich, J., Schäfer, K., \& Jennewein, M. (1987). Toward a consistent design of structural concrete. PCI Journal, 32, $74-150$.

Yun, Y. M. (2006). Strength of two-dimensional nodal zones in strut-tie models. Journal of the Structural Engineering. American Society of Civil Engineers, 132, 1764-1783. https://doi.org/10.1061/(ASCE)0733-9445(2006)132: 11(1764). 